\title{
The impact of social deprivation on mortality following hip fracture in England and Wales: a record linkage study
}

\author{
K. Thorne $^{1}$ • A. Johansen ${ }^{1,2}$ • A. Akbari ${ }^{1}$ - J. G. Williams ${ }^{1}$ - S. E. Roberts ${ }^{1}$
}

Received: 30 September 2015 / Accepted: 1 March 2016

(C) The Author(s) 2016. This article is published with open access at Springerlink.com

\begin{abstract}
Summary We used routine hospital data to investigate whether socially deprived patients had an increased risk of dying following hip fracture compared with affluent patients. We found that the most deprived patients had a significantly increased risk of dying at 30,90 and 365 days compared with the most affluent patients.

Introduction To identify whether social deprivation has any effect on mortality risk after emergency admission with hip fracture and to determine whether any increased mortality observed among deprived groups was associated with patient and hospital-related factors.

Methods We used routine, linked hospital inpatient and mortality data for emergency admissions with a hip fracture in both England and Wales between 2004 and 2011. Mortality rates at 30, 90 and 365 days were reported. Logistic regression was used to identify any significant increases in mortality with higher levels of social deprivation and the influence of other risk factors on any increased mortality among the most deprived group.

Results Mortality rates at 30, 90 and 365 days were 9.3, 17.4 and $29.0 \%$ in England and 8.3, 16.1 and $27.9 \%$ in Wales. Social deprivation was significantly associated with increased mortality in the most deprived quintile compared with the least deprived quintile at 30,90 and 365 days in England
\end{abstract}

K. Thorne

k.thorne@swansea.ac.uk

1 Swansea University Medical School, Swansea University, Singleton Park, Swansea SA2 8PP, UK

2 Trauma Unit, University Hospital of Wales, Heath Park, Cardiff CF14 4XW, UK
$(\mathrm{OR}=1.187,1.185$ and 1.154 , respectively $)$ and at 90 and 365 days in Wales (1.135 and 1.203). There was a little interaction between deprivation and other risk factors influencing 30- and 365-day mortality except for patient age, pre-fracture residence and hospital size.

Conclusions We demonstrated a positive association between social deprivation and increased mortality at 30 days postadmission for hip fracture in both England and Wales that was still evident at 90 and 365 days. We found little influence of other factors on social inequalities in mortality risk at 30 and 365 days post-admission.

Keywords Hip fracture $\cdot$ Mortality $\cdot$ Risk factors $\cdot$ Social deprivation

\section{Introduction}

There were approximately 75,000 hip fractures in the UK in 2012 and this figure is expected to increase in proportion to the number of elderly individuals in the population [1]. Many older people recovering from a hip fracture have coexisting medical, orthopaedic, psychological or social problems that can make operation and rehabilitation a challenge [2]. Approximately one third of patients will die within 1 year of their hip fracture [2,3], with mortality rates highest in males [4-8] and patients aged over 80 years [7, 8]. Most deaths are due to pre-existing illnesses rather than the fracture itself, reflecting the impact of comorbidities on mortality rates. It is well known that deprived patients tend to have multiple comorbidities [9]. Some research suggests that mortality rates are significantly higher for deprived patients when compared with more affluent patients following admission for hip fracture [6, $10-12]$ but there is also evidence of no association $[13,14]$. 
Studies have reported advancing age, male gender $[6,10]$, delays to surgery and comorbidities [10] as independent predictors of mortality in deprived patients but, to date, few studies have examined the impact of socioeconomic inequalities, and those that have do not provide a consensus. Additionally, there has been little published research on the impact of time on surgery, patient residence prior to their fracture, timing of admission or hospital size. We hypothesise that these factors may contribute to an increase in 30- and 365-day mortality rates in the most deprived quintile compared to the least deprived as a consequence of the poor pre-existing physical status, living conditions and access to services for the majority of people residing in deprived areas.

With no clear consensus available, we investigated associations between social deprivation and mortality following hip fracture in two comparable populations in the UK, England (population 53 million) and Wales (3 million), using the smaller Welsh population to compare the standard error effects across two similar countries with independently collected data sources. Our first objective was to determine whether there was any increased mortality at 30,90 and 365 days following admission according to increasing social deprivation. Secondly, we determined whether any increased mortality for deprived groups may be affected by factors such as patient age and gender, timing of admission, time to surgery, the presence of dementia, patient's pre-fracture residence and hospital size.

\section{Methods}

\section{Study design}

We used systematic record linkage of national inpatient and mortality data across England and Wales. All records were accessed through the Secure Anonymised Information Linkage (SAIL) databank, which holds records of inpatient admissions in England (Hospital Episode Statistics-HES) and Wales (Patient Episode Database for Wales-PEDW). All records were linked using a unique anonymised linking field (ALF) in Wales and encrypted Hospital Episode Statistic Identifier (HESID) in England that had been attached to the records of each patient using the patient's National Health Service (NHS) number or other fields such as date of birth, gender or postcode by applying a probabilistic matching algorithm. More details on the SAIL databank and the MACRAL methodology can be found elsewhere $[15,16]$.

To identify all deaths that occurred following discharge from hospital as well as in hospital, inpatient data were systematically linked to death certificate data from the Office for National Statistics (ONS). For Wales, we also used the Welsh Demographic Service (formerly known as the Welsh
Administrative Register) which also registers deaths for confirmatory purposes.

\section{Inclusion and exclusion criteria}

We selected all emergency admissions to English and Welsh hospitals where hip fracture was recorded as the principal diagnosis on the discharge record. The International Classification of Diseases 10th revision (ICD-10) codes used for hip fracture were S72.0 (fracture of neck of femur), S72.1 (pertrochanteric fracture) and S72.2 (subtrochanteric fracture). We also included S72.9 (fracture of femur, part unspecified) for patients aged $66+$ years on admission, but excluded these fractures of unspecified parts of the femur in people aged under 66 as most would refer to fractures of the shaft (e.g. through sporting and traffic injuries) rather than the neck of the femur.

We included patients aged 18 years or over, admitted between January 1, 2004 and December 31, 2011 and followed them up for 12 months to December 31, 2012. Admissions were excluded if they were not emergencies (e.g. elective) or if they occurred within 365 days of a previous hip fracture admission's discharge date.

\section{Mortality}

Mortality rates at 365 days following the admission were used as the primary outcome measure to determine the short-term impact of social deprivation following hip fracture, with mortality at 30 and 90 days as secondary outcome measures. We included deaths from all causes occurring during the inpatient stay and following discharge.

\section{Social deprivation}

To measure deprivation, we used the Indices of Multiple Deprivation (IMD) 2007 [17] for England and the Welsh Index of Multiple Deprivation (WIMD) 2008 for Wales [18], both of which have been explicitly designed for assigning area-based levels of deprivation to allow socioeconomic evaluations of local and national populations and are updated regularly to reflect the current population. IMD 2007 consists of seven separate domains of deprivation: income (22.5\%), employment $(22.5 \%)$, health and disability (13.5\%), education skills and training (13.5\%), barriers to housing and services $(9.3 \%)$, crime $(9.3 \%)$ and living environment $(9.3 \%)$ and is based on 32,482 Lower Super Output Areas (LSOAs; average population $=1500$ each). The WIMD 2008 also consists of seven separate domains of deprivation: 'income' ( $23.5 \%$ contribution), 'employment' (23.5\%), 'health' (14\%), 'education' (14\%), 'access to services' (10\%), 'housing' (5\%), 'physical environment' (5\%) and 'community safety' (5\%) and is based on 1896 LSOAs. Both indexes provide a 
deprivation score which was ranked and assigned to one of the five deprivation quintiles ( $\mathrm{I}=$ least deprived and $\mathrm{V}=$ most deprived quintile).

\section{Risk factors}

We assessed a number of key risk factors to determine whether they significantly mediated the relationship between social deprivation and mortality at both 30 and 365 days following admission by using logistic regression. We analysed the impact on mortality for each risk factor, stratified by each subgroup within that risk factor, comparing the least and most deprived cases, using the least deprived quintile as the reference group.

\section{Patient demographics}

The patient's age on admission was collected for each case. Age was grouped into $<65$ years, 65 to 74 years, 75 to 84 years and $85+$ years. The patient's gender was also recorded.

\section{Timing of admission}

We investigated any impact of the day of admission on mortality by assigning weekdays (Monday 00:00 to Friday 23:59), weekends (Saturday 00:00 to Sunday 23:59) and public holidays (eight per year) which were prioritised over weekdays and weekends in this classification. We also investigated the season of admission (winter $=$ Dec to Feb; spring $=$ Mar to May; summer = Jun to Aug; autumn = Sept to Nov) and calendar years of admission (grouped by 2004-2005, 20062008 and 2009-2011).

\section{Hospital size}

Hospital size at the time of admission was collected from the Health and Social Care Information centre (HSCIC) for England and from Statistics for Wales (StatsWales) for Welsh patients and grouped into 100-399 (small hospital), 400-599 (medium) or 600+ beds (large).

\section{Time to surgery}

Time to surgery was calculated by determining the difference between the admission date and the date of the first hip fracture-related operation, using the following Office of Population Censuses and Surveys Classification of Surgical Operations and Procedures (4th revision) (OPCS-4) codes: W19.1 (primary open reduction of fracture of neck of femur and open fixation using pin and plate), W24.1 (closed reduction of intracapsular fracture of neck of femur and fixation using nail or screw), W37-W39 (total prosthetic replacement), W46-W48 (prosthetic replacement of head of femur),
W58 (resurfacing of hip joint) or W93-95 (hybrid prosthetic replacement). Some of these procedures are performed for other indications (e.g. osteoarthritis), but we included them only when they had been performed as part of the emergency hip fracture admission. We grouped the time to surgery into three categories to reflect NICE guidelines [1], namely surgery on the day of admission or the next day, on the third day or after the third day.

\section{Dementia}

In our analysis, we defined dementia using ICD-10 codes F00-F03, F05.1 and G30, during the index admission or any admission during the previous 5 years.

\section{Pre-fracture residence}

As a proxy for pre-fracture mobility, we categorised patients according to their pre-fracture residence: whether they had previously been living in their own home, in a nursing/ residential care home or were transferred from another hospital.

\section{Patient comorbidities}

When investigating mortality, we also adjusted for the impact of age group, gender and comorbidities. Specifically, we adjusted for any impact of the following 11 major patient comorbidities using ICD-10 codes recorded in any diagnostic position during the admission or within the previous 5 years from inpatient care records where available: ischaemic heart disease (ICD-10 I20-I25) or other cardiovascular diseases (I00-I15, I26-I52), cerebrovascular disease (I60-I69), other circulatory diseases (I70-I99), malignancies (C00-C97), chronic obstructive pulmonary disease (COPD) (J40-J44), asthma (J45-J46), diabetes (E10-E14), dementia (F00-F03, F05.1, G30), liver disease (K70-K77) and renal failure (N17-N19).

\section{Methods of analysis}

The main study outcome measures were percentage mortality rates, the odds of mortality for the most deprived versus the least deprived and impact of risk factors at 30, 90 and 365 days following admission for each condition using logistic regression.

We reported key demographic characteristics for the most and least deprived cases including age, gender, fracture type and comorbidities and tested for statistical significance using independent sample $t$ tests and Pearson's chi-squared tests. Significance was measured at the conventional $5 \%$ level.

Logistic regression was also used to establish how any higher mortality for deprived groups at 30 and 365 days may be correlated with the following key risk factors: patient 
age and gender, whether the patient had dementia, the day type, season and year group of admission, hospital size, time to surgery and pre-fracture residence. To do this, we compared mortality in the least and most deprived quintiles, using the least deprived quintile as the reference category, for each stratum of each risk factor. The logistic regression mortality odds ratios were presented with $95 \%$ confidence intervals. Significance was measured at the conventional $5 \%$ level. Thirdly, logistic regression was used to test for any interaction effects on mortality between social deprivation and each of the study risk factors. This would highlight whether there were any significant differences between the mortality odds ratios within each risk factor.

All logistic regression analyses were adjusted for age, gender and the 11 patient comorbidities. We also adjusted the model so that patients with no previous inpatient admissions in the last 5 years, meaning no comorbidities were recorded, did not bias the results.

A Bonferroni correction was applied to account for multiple statistical tests. Results were displayed in tables to indicate whether they were significant before and after the correction was applied.

\section{Results}

Between January 2004 and December 2011, there were 455, 862 people admitted with hip fracture in England and 29,733 in Wales.

In England, the mean age at admission was 80.7 years \pm 11.6 and males accounted for $26.2 \%$ of cases. In Wales, the mean age was 80.4 years \pm 11.1 and males accounted for $25.9 \%$ of cases.

Gender was missing for eight cases from England and no cases from Wales. Social deprivation scores could not be calculated for 5447 cases who did not live in England but were admitted to English hospitals, and 966 cases who did not live in Wales but were admitted to Welsh hospitals. These were not included in the analyses. No other data items in the analysis were missing from the dataset.

\section{Baseline differences between affluent and deprived quintiles}

We found significant differences between the most affluent and the least deprived quintiles for mean age at admission, fracture type and many comorbidities and, for England only, gender and hospital length of stay (see Table 1). When compared with the least deprived cases, the most deprived cases were more likely to be male, younger, presenting with trochanteric fractures and, with the exception of malignancies, were more likely to have comorbidities.
In England, they also had a longer inpatient stay, though we did not observe this in Wales.

\section{Mortality, demographics and social deprivation}

In England, mortality at 30 days was $9.3 \%$, at 90 days was $17.4 \%$ and at 365 days was $29.0 \%$ whilst in Wales, the rates were $8.3,16.1$ and $27.9 \%$, respectively.

Mortality rates at 30 days were highest in the over 85 age group (13.6\% in England and $11.5 \%$ in Wales) and higher in men (12.2\% in England and $11.0 \%$ in Wales) compared with women (8.3 and $7.4 \%)$. After Bonferroni corrections were applied, social deprivation was significantly associated with an increase in mortality at 30 days in England (most deprived $=1.187$ compared with least deprived) but the increase was not significant in Wales (1.136). At 90 and 365 days, mortality rates were significantly increased in both populations (1.185 and 1.154 in England, and 1.135 and 1.203 in Wales; see Table 2).

\section{Effect of factors on the increased 365-day mortality with social deprivation}

Tables 3 and 4 report the mortality rates for quintiles I and V, along with the adjusted 30- and 365-day mortality risk associated with each of the factors listed for England and Wales, respectively.

\section{Patient demographics}

There was a significant interaction with age group at 30 and 365 days in England $(p<0.001$ for both time points) and Wales $(p<0.001$ and $p=0.008$, respectively), with patients aged over 85 in the most deprived quintile showing a significant and lower odds ratio than the other age groups at 30 and 365 days in England (see Table 3) and Wales (see Table 4).

There was also a significant interaction with gender at 30 days in England ( $p=0.001)$, with females in the most deprived quintile having a significantly higher mortality risk. There was no significant interaction effect at 365 days, with males and females showing similar mortality risk. In Wales, males had a higher risk at 30 days and females at 365 days, and neither of which showed a significant interaction effect.

\section{Timing of admission}

There was a significant interaction effect with weekday at 30 days in Wales $(p=0.024)$, with patients in the most deprived quintile (compared with the least deprived quintile) admitted Monday-Friday having a significantly higher mortality risk than those admitted at the weekend or public 
Table 1 Demographics of patients in the least and most deprived quintiles for England and Wales

\begin{tabular}{|c|c|c|c|c|c|c|}
\hline & \multicolumn{3}{|l|}{ England } & \multicolumn{3}{|l|}{ Wales } \\
\hline & Least deprived & Most deprived & Sig. & Least deprived & Most deprived & Sig. \\
\hline No. of cases & 86,148 & 85,422 & & 5333 & 5765 & \\
\hline Mean age in years (SD) & $81.5(10.9)$ & $78.8(12.7)$ & $<0.001$ & $81.5(10.3)$ & $79.2(11.6)$ & $<0.001$ \\
\hline \multicolumn{7}{|l|}{ Gender $^{\mathrm{a}}$} \\
\hline Male & $25.7 \%$ & $28.6 \%$ & $<0.001$ & $26.0 \%$ & $27.5 \%$ & 0.079 \\
\hline Female & $74.3 \%$ & $71.4 \%$ & & $74.0 \%$ & $72.5 \%$ & \\
\hline $\begin{array}{l}\text { 30-day mortality rate } \\
\text { (crude \%) }\end{array}$ & $8.5 \%$ & $9.7 \%$ & & $8.2 \%$ & $9.2 \%$ & \\
\hline $\begin{array}{l}\text { 90-day mortality rate } \\
\text { (crude \%) }\end{array}$ & $16.2 \%$ & $18.1 \%$ & & $15.9 \%$ & $17.2 \%$ & \\
\hline $\begin{array}{l}\text { 365-day mortality rate } \\
\text { (crude \%) }\end{array}$ & $27.3 \%$ & $30.1 \%$ & & $26.5 \%$ & $29.8 \%$ & \\
\hline \multicolumn{7}{|l|}{ Fracture type } \\
\hline Fracture of neck of femur & $73.6 \%$ & $71.7 \%$ & $<0.001$ & $72.8 \%$ & $67.8 \%$ & $<0.001$ \\
\hline Pertrochanteric fracture & $22.3 \%$ & $24.3 \%$ & & $23.7 \%$ & $28.3 \%$ & \\
\hline Subtrochanteric fracture & $3.2 \%$ & $3.2 \%$ & & $2.9 \%$ & $3.3 \%$ & \\
\hline Fracture of femur, part unspecified & $0.8 \%$ & $0.8 \%$ & & $0.6 \%$ & $0.6 \%$ & \\
\hline Mean spell duration (SD) & $21.6(22.5)$ & $24.7(25.4)$ & $<0.001$ & $23.9(33.2)$ & $23.6(30.6)$ & 0.704 \\
\hline \multicolumn{7}{|l|}{ Comorbidities during previous 5 years } \\
\hline Acute myocardial infarction & $5.5 \%$ & $6.5 \%$ & $<0.001$ & $6.8 \%$ & $7.1 \%$ & 0.525 \\
\hline Cerebrovascular disease & $13.6 \%$ & $15.7 \%$ & $<0.001$ & $17.4 \%$ & $18.2 \%$ & 0.275 \\
\hline Other circulatory disease & $18.0 \%$ & $21.1 \%$ & $<0.001$ & $30.9 \%$ & $31.8 \%$ & 0.316 \\
\hline Malignancies & $13.2 \%$ & $12.7 \%$ & 0.003 & $16.2 \%$ & $14.5 \%$ & 0.011 \\
\hline Liver disease & $1.6 \%$ & $3.3 \%$ & $<0.001$ & $1.4 \%$ & $2.9 \%$ & $<0.001$ \\
\hline COPD & $8.9 \%$ & $18.8 \%$ & $<0.001$ & $13.0 \%$ & $21.7 \%$ & $<0.001$ \\
\hline Asthma & $8.1 \%$ & $11.7 \%$ & $<0.001$ & $9.9 \%$ & $14.8 \%$ & $<0.001$ \\
\hline Diabetes & $11.6 \%$ & $15.3 \%$ & $<0.001$ & $13.0 \%$ & $16.9 \%$ & $<0.001$ \\
\hline Renal failure & $10.8 \%$ & $13.5 \%$ & $<0.001$ & $10.6 \%$ & $11.1 \%$ & 0.375 \\
\hline Dementia & $23.1 \%$ & $24.3 \%$ & $<0.001$ & $22.1 \%$ & $23.8 \%$ & 0.042 \\
\hline
\end{tabular}

Significance was measured at the $5 \%$ level using chi-squared tests or $t$ tests

All significant results are set in italic

${ }^{\text {a }}$ Gender was missing for eight cases in England

holidays. However, there was no significant interaction effect at 365 days, nor for England at 30 or 365 days.

\section{Hospital size}

There was a significant interaction effect with hospital size at 30 and 365 days in England ( $p=0.029$ and $p<0.001$, respectively) and for 365 days in Wales $(p=0.006)$.

In England, mortality risk for patients from the most deprived quintile was greatest for large $(600+$ beds) hospitals at both 30 and 365 days. The medium-sized hospitals had the lowest risk of all at 30 and 365 days. In Wales, there was no significant interaction effect at 30 days but at 365 days, the small hospitals (100-399 beds) had a significantly higher mortality risk than the other hospital groups.
Time to surgery

Next day, surgery had the highest odds ratio for 30 and 365 days in England and 30 days in Wales, but there was no significant interaction effect between social deprivation and time to surgery at 30 or 365 days for England or Wales.

\section{Dementia}

In England, there were insufficient numbers to calculate the odds ratio for patients with dementia who died within 30 days. At 365 days, not having dementia appeared to significantly increase the mortality risk for the most deprived compared with the least deprived quintile. In Wales, the same effect 
Table 2 Thirty-day mortality odds ratios at 30, 90 and 365 days following hip fracture according to age, gender and social deprivation, 2004 to 2012

\begin{tabular}{|c|c|c|c|c|}
\hline \multicolumn{2}{|l|}{ Risk factor } & \multirow{2}{*}{$\begin{array}{l}\text { Adjusted } † 30 \text {-day } \\
\text { OR }(95 \% \text { CI })\end{array}$} & \multirow{2}{*}{$\begin{array}{l}\text { Adjusted } \uparrow 90 \text {-day } \\
\text { OR }(95 \% \text { CI })\end{array}$} & \multirow{2}{*}{$\begin{array}{l}\text { Adjusted } † 365 \text {-day } \\
\text { OR }(95 \% \text { CI })\end{array}$} \\
\hline \multicolumn{2}{|l|}{ England } & & & \\
\hline \multirow[t]{2}{*}{ Gender $^{\mathrm{a}}$} & Male & Reference & Reference & Reference \\
\hline & Female & $0.608(0.595,0.622)^{*}$ & $0.641(0.629,0.653)^{*}$ & $0.651(0.640,0.661)^{*}$ \\
\hline \multirow[t]{5}{*}{ Social deprivation $^{\mathrm{b}}$} & I (least deprived) & Reference & Reference & Reference \\
\hline & II & $1.094(1.058,1.131)^{*}$ & $1.075(1.048,1.104)^{*}$ & $1.046(1.023,1.070)^{*}$ \\
\hline & III & $1.116(1.079,1.153)^{*}$ & $1.097(1.069,1.126)^{*}$ & $1.075(1.052,1.099)^{*}$ \\
\hline & IV & $1.157(1.119,1.196)^{*}$ & $1.153(1.123,1.183)^{*}$ & $1.122(1.097,1.147)^{*}$ \\
\hline & V (most deprived) & $1.187(1.147,1.228)^{*}$ & $1.185(1.154,1.217)^{*}$ & $1.154(1.128,1.181)^{*}$ \\
\hline \multicolumn{5}{|l|}{ Wales } \\
\hline \multirow[t]{2}{*}{ Gender } & Male & Reference & Reference & Reference \\
\hline & Female & $0.641(0.583,0.705)^{*}$ & $0.664(0.616,0.714)^{*}$ & $0.661(0.620,0.705)^{*}$ \\
\hline \multirow[t]{5}{*}{ Social deprivation $^{\mathrm{b}}$} & I (least deprived) & Reference & Reference & Reference \\
\hline & II & $0.993(0.863,1.142)$ & $0.970(0.871,1.081)$ & $1.093(0.998,1.198)$ \\
\hline & III & $0.981(0.856,1.123)$ & $1.046(0.943,1.160)$ & $1.132(1.037,1.237)$ \\
\hline & IV & $0.963(0.838,1.106)$ & $1.089(0.981,1.209)$ & $1.151(1.053,1.259)$ \\
\hline & V (most deprived) & $1.136(0.991,1.302)$ & $1.135(1.022,1.261)$ & $1.203(1.100,1.317)^{*}$ \\
\hline
\end{tabular}

Italic font denotes significance at the $5 \%$ level

* Denotes significance after applying a Bonferroni correction for each condition $(p \leq 0.00167)$

$\dagger$ The OR for gender is adjusted for age group and comorbidities. All other factors were adjusted for age group, gender and comorbidities

${ }^{\text {a }}$ Gender was missing for 26 cases in England

${ }^{\mathrm{b}}$ Social deprivation scores were missing for 5447 cases in England and 966 cases in Wales

was seen at 365 days but at 30 days, neither odds ratio was significant. There were no significant interaction effects noted.

\section{Pre-fracture residence}

There was a significant interaction effect for 30-day mortality in England and both 30- and 365-day mortality in Wales. In England, patients from the most deprived quintile admitted from their own home had a significantly higher 30-day mortality risk than patients admitted from a nursing or residential home, or who were transferred in. At 365 days, the mortality risk was still the highest in this group but not significantly so. In Wales, there was a significantly higher risk of 30and 365-day mortality for patients transferred to the hospital.

\section{Discussion}

We found that social deprivation was significantly associated with higher mortality at 30,90 and 365 days following an emergency admission for hip fracture in England and at 90 and 365 days in Wales. We also found that patient age, hospital size and pre-fracture residence were significantly associated with mortality in those who were from deprived areas in both populations.

Our 30-day mortality rates of $9.3 \%$ in England and $8.3 \%$ in Wales were comparable with those reported by other hip fracture studies in the UK [10, 19-23]. The same was true for our 365-day mortality rates of $29.0 \%$ in England and $27.9 \%$ in Wales [21-25]. The significant association we found between mortality risk and social deprivation has also been reported by other UK [3, 6, 10, 26] and international [6] studies.

Our data showed that deprived patients were younger on admission. The influence of age on mortality after hip fracture has been extensively described [4-8,10,21, 27-30], and our study suggests that the increased mortality risk seen in these deprived patients reflects an increased rate of comorbidities compared to the most affluent patients - a trend that has been reported by others [12].

Other key predictors of mortality following hip fracture include male gender [4-8, 10, 21, 27-30], comorbidities [4, $8,31,32]$, dementia [8, 30], osteoporosis [4], fracture severity $[8,21,27,31]$, surgical delays $[10,32]$ and post-operative complications [32], living in a nursing or residential home [8], poor pre-injury walking capacity [8] and poor social contact [7]. We hypothesised that many of these predictors would be influenced by patients' social deprivation status and might increase mortality risk for the most deprived patients. 


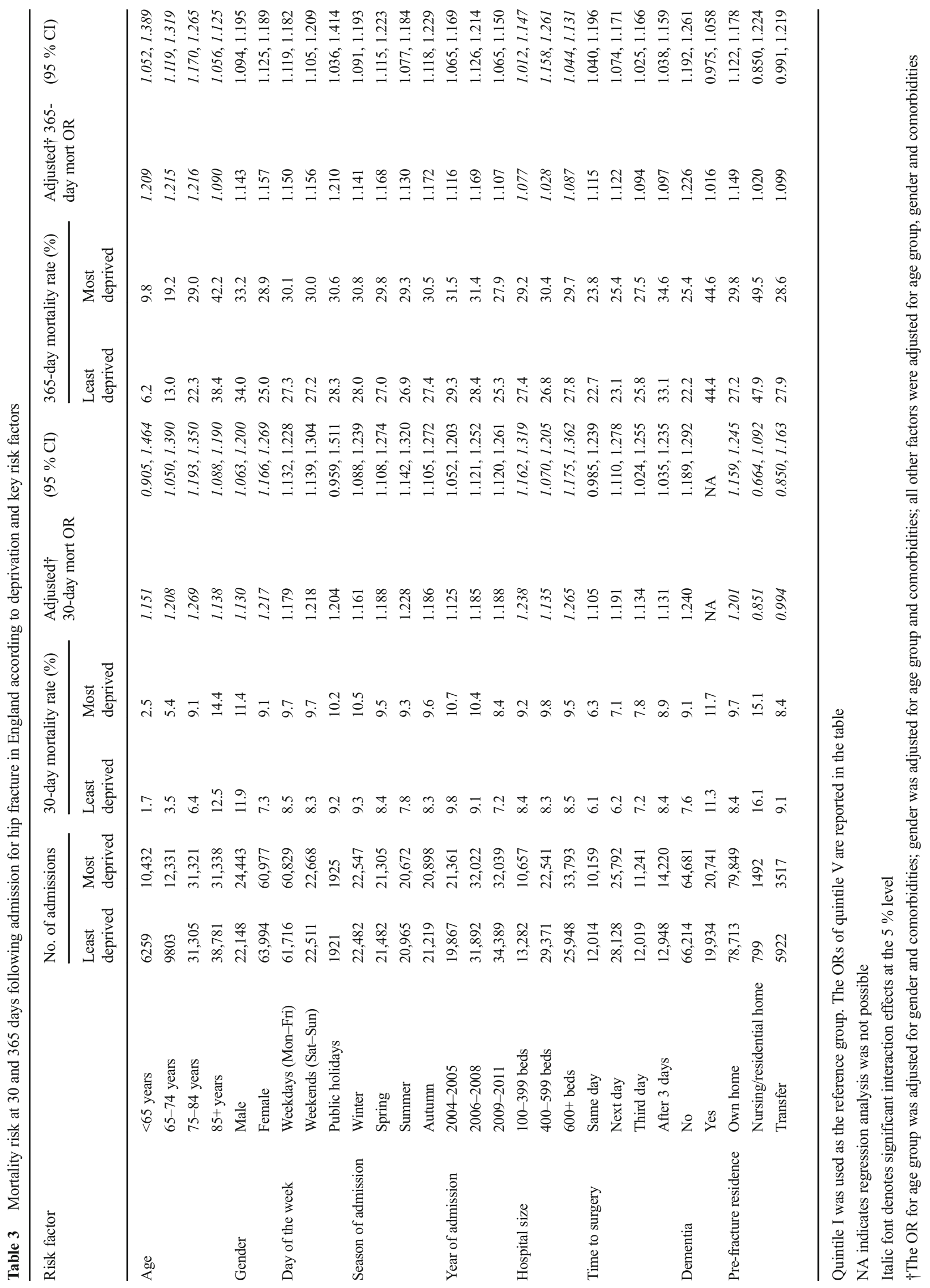




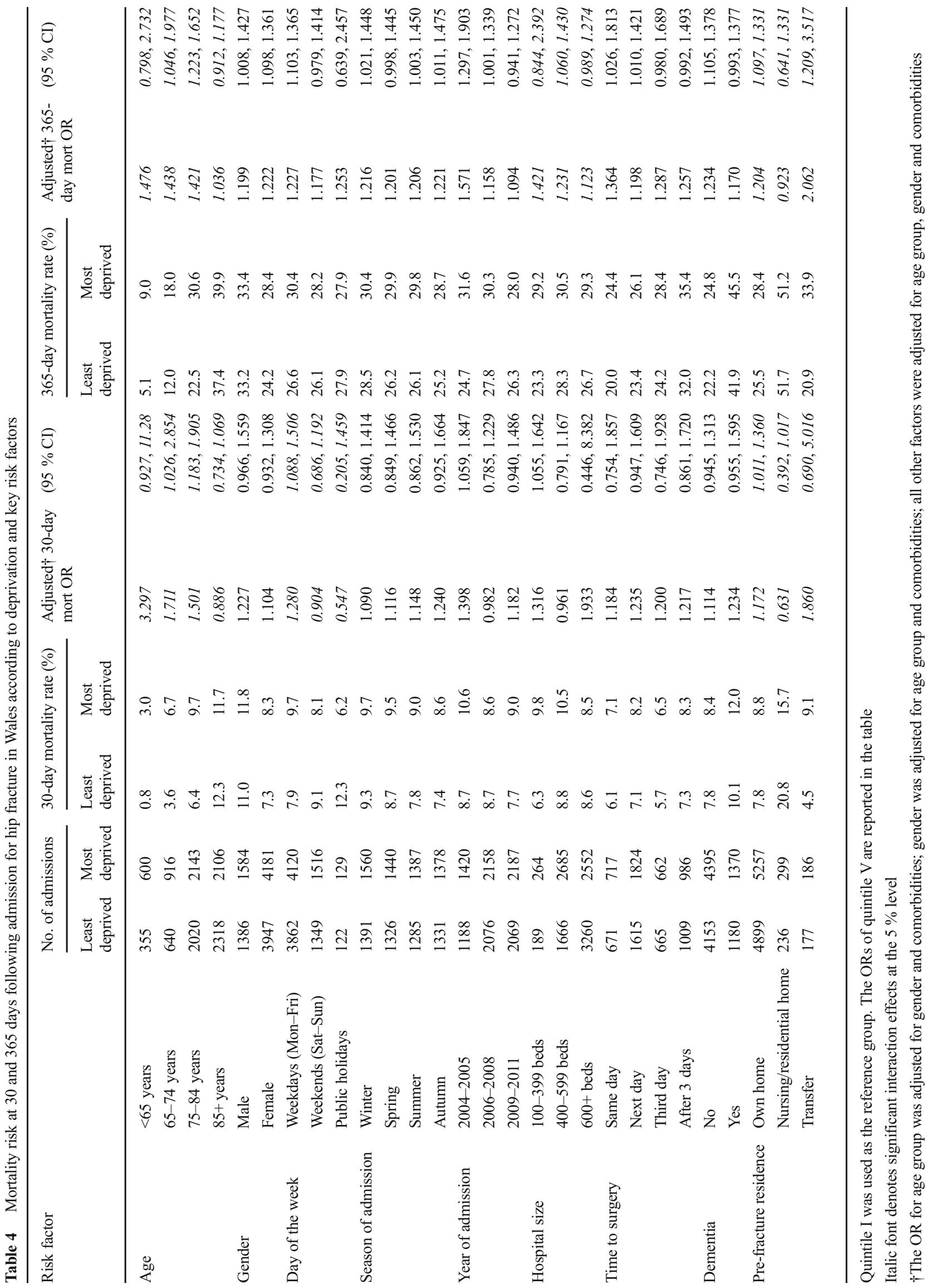


Unfortunately, HES and PEDW do not capture facture severity, walking capacity, post-operative complications or social contact, and comorbidities are not rigorously recorded on records in either country. For example, only $10 \%$ of women with a hip fracture had osteoporosis recorded as a comorbidity. Consequently, we were unable to include these factors into any analyses.

Dementia has been reported as playing a major role in increasing mortality risk in patients with hip fracture as patients have a lower probability of functional recovery at discharge and 6 months post-discharge [33]. Our study showed an increased risk of mortality within 30 days, but not at 365 days, suggesting that the impact of dementia is most crucial during the acute admission, surgery and rehabilitation.

Mortality risk was significantly different in England at 30 and 365 days with the largest hospitals showing the higher mortality rates for deprived patients. In Wales, higher mortality rates were seen in the largest hospitals at 30 days, although this was not significantly different to the other hospital groups. However, at 365 days, it was the smaller hospitals whose mortality rates were significantly higher than the other groups.

Time to surgery and complications after surgery contribute to increased mortality rates. Whilst we were able to investigate the impact of surgical delays according to deprivation status, the administrative data lacked sufficient detail to explore post-operative complications, but there is evidence to suggest that low income is associated with a higher risk of acute medical events and infections [13]. Our data showed that the most deprived patients had a higher mortality rate following surgery than the most affluent patients at 30 and 365 days, and that this difference increased with greater delay to surgery. However, there was no significant interaction effect, so we cannot conclude that the mortality risks were significantly different according to time to surgery. A metaanalysis of hip fracture studies reported that operating beyond $48 \mathrm{~h}$ may increase the odds of 30-day mortality by $41 \%$ and of 365 -day mortality by $32 \%$ [34], but this remains a complex question since many delays to surgery are a consequence of comorbidities that need assessment or treatment before surgery and anaesthesia can go ahead [35]. People from deprived areas are known to be at higher risk of multiple comorbidities than their affluent counterparts [9], but there is also evidence that socioeconomic deprivation is associated with lower rates of early intervention $[6,13]$. If so, then the additional delays experienced by deprived patients might result in higher mortality rates for this group.

The patient's residence pre-injury will affect mortality risks, with people admitted from a nursing or residential care home, experiencing higher mortality [21]. When we examined patients' pre-admission residence, we found that in England, 30- and 365-day mortality rates for people admitted from home were higher for deprived than for affluent patients, significantly so at 30 days. In Wales, the highest mortality at both 30 and 365 days was seen in deprived patients transferred to the hospital from another healthcare provider, compared with affluent patients.

Major strengths of the study are its size, covering more than 455,000 cases of hip fracture in England and 29,700 in Wales. The methodology was based on systematic, validated record linkage of inpatient and death certificate to identify all admissions and all deaths that occur during the inpatient stay and following discharge from hospital. Finally, using Welsh data allowed us to compare our findings in a similar, albeit smaller population.

As with other large-scale studies that used NHS administrative health data, this study lacked detailed information about patient disease history or any severity indicators. We were also unable to determine the exact time elapsed until surgery was performed as this information is only recorded at date level with no time field available in either HES or PEDW. We did not combine both populations as the measures of deprivation used in each country were based on different domains with no validated method for merging the two.

Whilst the inclusion of alcohol and substance abuse would have been useful additions to our modelling, the quality of that data was extremely poor and could not be used. Additionally, we were unable to use the Charlson Comorbidity Index in accordance with its requirements as the UK regulations prohibit the access of HIV status in routine data. However, the comorbidities used in this study were based on other measures in that index wherever possible.

Social deprivation refers to problems caused by a general lack of resources and opportunities and not just money. The association between social deprivation and increased mortality risk is multifaceted, and a patient's pre-existing and baseline clinical and psychological status may contribute to any relationship between social deprivation and mortality. Mortality following hip fracture is usually attributed to underlying ill health [1], but poor social contact pre-injury has also been linked with increased mortality risk [7], and other deprivation-related factors including reduced resources, lower education status, poor lifestyle and social contact, reduced likelihood of preventative medication, and poor mental health, particularly dementia, may also play a part. However, when interpreting these findings of an association between deprivation and increased mortality, it is important to remember the ecological fallacy: not everyone living in a deprived area is deprived, and that not all deprived people live in deprived areas.

\section{Conclusions}

We have demonstrated a clear association between social deprivation and increased mortality following emergency admission for hip fracture in the two UK populations. The study findings also suggest that patient age, hospital size and prefracture residence are factors that play a part in this association in both English and Welsh populations. 
Acknowledgments This work was supported by the Wellcome Trust [Grant No: 093564/Z/10/Z]. The funding body had no role in study design; in the collection, analysis and interpretation of data; in the writing of the report; and in the decision to submit the manuscript for publication.

The Office for National Statistics (ONS) provided the mortality data in this study but was not responsible for the further analysis or interpretation.

We acknowledge the support from The Farr Institute CIPHER. The Farr Institute CIPHER is supported by a 10 -funder consortium: the Arthritis Research UK, the British Heart Foundation, the Cancer Research UK, the Economic and Social Research Council, the Engineering and Physical Sciences Research Council, the Medical Research Council, the National Institute of Health Research, the National Institute for Social Care and Health Research (Welsh Assembly Government), the Chief Scientist Office (Scottish Government Health Directorates) and the Wellcome Trust (MRC Grant No: MR/K006525/1)

\section{Compliance with ethical standards}

Funding This work was supported by the Wellcome Trust [Grant No: 093564/Z/10/Z]. The views expressed in this paper are those of the authors and not necessarily those of the funding body.

\section{Conflicts of interest None.}

Open Access This article is distributed under the terms of the Creative Commons Attribution 4.0 International License (http:// creativecommons.org/licenses/by/4.0/), which permits use, duplication, adaptation, distribution and reproduction in any medium or format, as long as appropriate credit is given to the original author(s) and the source, a link is provided to the Creative Commons license and any changes made are indicated.

\section{References}

1. National Institute of Health and Care Excellence (2011) Hip fracture: the management of hip fracture in adults. http://www.nice.org. uk/guidance/CG124 2015

2. National Hip Fracture Audit (2014) Falls and Fragility Fracture Audit Programme (FFFAP): National Hip Fracture Database extended report. Royal College of Physicians, London, p 102

3. Roberts SE, Goldacre MJ (2003) Time trends and demography of mortality after fractured neck of femur in an English population, 1968-98: database study. BMJ 327:771-775

4. Diamantopoulos AP, Hoff M, Hochberg M, Haugeberg G (2013) Predictors of short- and long-term mortality in males and females with hip fracture - a prospective observational cohort study. PLoS One 8:e78169

5. Dubljanin-Raspopović E, Marković-Denić L, Marinković J, Nedeljković U, Bumbaširević M (2013) Does early functional outcome predict 1-year mortality in elderly patients with hip fracture? Clin Orthop Relat Res 471:2703-2710

6. Barone AP, Fusco D, Colais P, D'Ovidio M, Belleudi V, Agabiti N, Sorge C, Davoli M, Perucci CA (2009) Effects of socioeconomic position on 30-day mortality and wait for surgery after hip fracture. Int J Qual Health Care 21:379-386

7. Mortimore E, Haselow D, Dolan M, Hawkes WG, Langenberg P, Zimmerman S, Magaziner J (2008) Amount of social contact and hip fracture mortality. J Am Geriatr Soc 56:1069-1074

8. Hu F, Jiang C, Shen J, Tang P, Wang Y (2012) Preoperative predictors for mortality following hip fracture surgery: a systematic review and meta-analysis. Injury 43:676-685
9. Charlton J, Rudisill C, Bhattarai N, Gulliford M (2013) Impact of deprivation on occurrence, outcomes and health care costs of people with multiple morbidity. J Health Serv Res Policy 18:215-223

10. Bottle A, Aylin P (2006) Mortality associated with delay in operation after hip fracture: observational study. BMJ 332:947-951

11. Wu TY, Jen MH, Bottle A, Liaw CK, Aylin P, Majeed A (2011) Admission rates and in-hospital mortality for hip fractures in England 1998 to 2009: time trends study. J Public Health (Oxf) 33:284-291

12. Clement ND, Muzammil A, Macdonald D, Howie CR, Biant LC (2011) Socioeconomic status affects the early outcome of total hip replacement. J Bone Joint Surg (Br) 93:464-469

13. Agabiti N, Picciotto S, Cesaroni G et al (2007) The influence of socioeconomic status on utilization and outcomes of elective total hip replacement: a multicity population-based longitudinal study. Int J Qual Health Care 19:37-44

14. Quah C, Boulton C, Moran C (2011) The influence of socioeconomic status on the incidence, outcome and mortality of fractures of the hip. J Bone Joint Surg (Br) 93:801-805

15. Lyons RA, Jones KH, John G, Brooks CJ, Verplancke JP, Ford DV, Brown G, Leake K (2009) The SAIL databank: linking multiple health and social care datasets. BMC Med Inform Decis Mak 9:3

16. Ford DV, Jones KH, Verplancke JP et al (2009) The SAIL Databank: building a national architecture for e-health research and evaluation. BMC Health Serv Res 9:157

17. Office for National Statistics (2007) Index of Multiple Deprivation (IMD) 2007. http://data.gov.uk/dataset/index of multiple deprivation_imd_2007. Accessed Aug 2015

18. Statistics for Wales Welsh Index of Multiple Deprivation (2008) http://gov.wales/docs/statistics/2008/080609wimd2008leafleten. pdf. Accessed Aug 2015

19. Barr LV, Vindlacheruvu M, Gooding CR (2015) The effect of becoming a major trauma centre on outcomes for elderly hip fracture patients. Injury 46:384-387

20. Gunasekera N, Boulton C, Morris C, Moran C (2010) Hip fracture audit: the Nottingham experience. Osteoporos Int 21:S647-S653

21. Johansen A, Mansor M, Beck S, Mahoney H, Thomas S (2010) Outcome following hip fracture: post-discharge residence and longterm mortality. Age Ageing 39:653-656

22. Moran CG, Wenn RT, Sikand M, Taylor AM (2005) Early mortality after hip fracture: is delay before surgery important? J Bone Joint Surg Am 87:483-489

23. Roche JJ, Wenn RT, Sahota O, Moran CG (2005) Effect of comorbidities and postoperative complications on mortality after hip fracture in elderly people: prospective observational cohort study. BMJ 331:1374

24. Withey C, Morris R, Beech R, Backhouse A (1995) Outcome following fractured neck of femur-variation in acute hospital care or case mix? J Public Health Med 17:429-437

25. Kalra S, Williams A, Whitaker R, Hossain M, Curtis G, Giles M, Sinha A, Bastawrous SS (2010) Subclinical thyroid dysfunction does not affect one-year mortality in elderly patients after hip fracture: a prospective longitudinal study. Injury 41:385-387

26. Smith P, Ariti C, Bardsley M (2013) Focus on hip fracture: trends in emergency admissions for fractured neck of femur, 2001 to 2011. London, p 28. http://www.health.org.uk/sites/default/files/ QualityWatch FocusOnHipFracture.pdf. Accessed Apr 2016

27. Bretherton CP, Parker MJ (2015) Early surgery for patients with a fracture of the hip decreases 30-day mortality. Bone Joint J 97-B:104-108

28. Pugely AJ, Martin CT, Gao Y, Klocke NF, Callaghan JJ, Marsh JL (2014) A risk calculator for short-term morbidity and mortality after hip fracture surgery. J Orthop Trauma 28:63-69

29. Frost SA, Nguyen ND, Black DA, Eisman JA, Nguyen TV (2011) Risk factors for in-hospital post-hip fracture mortality. Bone 49:553-558

30. Schürch MA, Rizzoli R, Mermillod B, Vasey H, Michel JP, Bonjour JP (1996) A prospective study on socioeconomic aspects of fracture of the proximal femur. J Bone Miner Res 11: 1935-1942 
31. Norring-Agerskov D, Laulund AS, Lauritzen JB, Duus BR, van der Mark S, Mosfeldt M, Jørgensen HL (2013) Metaanalysis of risk factors for mortality in patients with hip fracture. Dan Med J 60: A4675

32. Kenzora JE, McCarthy RE, Lowell JD, Sledge CB (1984) Hip fracture mortality: relation to age, treatment, preoperative illness, time of surgery, and complications. Clin Orthop Relat Res 186:45-56

33. Tarazona-Santabalbina FJ, Belenguer-Varea Á, Rovira Daudi E, Salcedo Mahiques E, Cuesta Peredó D, Doménech-Pascual JR, Gac
Espínola H, Avellana Zaragoza JA (2015) Severity of cognitive impairment as a prognostic factor for mortality and functional recovery of geriatric patients with hip fracture. Geriatr Gerontol Int 15:289-295

34. Shiga T, Wajima Z, Ohe Y (2008) Is operative delay associated with increased mortality of hip fracture patients? Systematic review, meta-analysis, and meta-regression. Can J Anaesth 55:146-154

35. Grimes JP, Gregory PM, Noveck H, Butler MS, Carson JL (2002) The effects of time-to-surgery on mortality and morbidity in patients following hip fracture. Am J Med 112:702-709 